Check for updates

Cite this: RSC Adv., 2018, 8, 36181

Received 24th August 2018

Accepted 16th October 2018

DOI: $10.1039 / c 8 r a 07073 c$

rsc.li/rsc-advances

\section{Adsorption and photo-Fenton catalytic degradation of organic dyes over crystalline $\mathrm{LaFeO}_{3}$-doped porous silica $\uparrow$}

\begin{abstract}
Thi To Nga Phan, Aleksandar N. Nikoloski, Parisa Arabzadeh Bahri and Dan Li (D) *
$\mathrm{LaFeO}_{3}$ (LFO)-doped mesoporous silica (HPS) (HPS- $x$ LFO with theoretical LFO/silica molar ratio $x=0.075$, $0.15,0.3)$ was successfully prepared via impregnation of metal ions into the porous silica HPS-OLFO support and subsequent calcination. The characterization studies suggest that increasing the doping of LFO, which exhibited a particle size of $\sim 10-15 \mathrm{~nm}$, in the silica support led to a reduction in surface area and bandgap of the resulting catalyst. The use of HPS-0.15LFO yielded a superior removal rate $(98.9 \%)$ of Rhodamine $B$ $(\mathrm{RhB})$, thanks to the effective dark adsorption and visible light-induced photo-Fenton degradation, both of which were greater than those of pure LFO crystals. This enhancement could be explained by the unique properties of the mesoporous silica support. In particular, the wide-opening mesopores created a large surface area to dope LFO as active sites and minimize diffusion of RhB into pores during the photo-Fenton reaction. The photo-Fenton catalytic degradation of $\mathrm{RhB}$ could reach $98.6 \%$ within 90 min exposure to visible light irradiation under optimized conditions: RhB concentration $=10 \mathrm{mg} \mathrm{L}^{-1}$, catalyst dosage $=1 \mathrm{~g} \mathrm{~L}^{-1}, \mathrm{pH}=6$ and $\mathrm{H}_{2} \mathrm{O}_{2}=15 \mathrm{mM}$. Moreover, the recycle and reuse test proved the good stability and repetitive use of HPS-0.15LFO for high performance RhB removal.
\end{abstract}

\section{Introduction}

Advanced oxidation processes (AOPs) have been considered as alternative and effective methods in treating various industrial wastewaters contaminated by dyes and organic compounds over the last few years. As one of the AOPs, the Fenton reaction, using the strong oxidant hydrogen peroxide to generate highly reactive hydroxyl radicals $\left({ }^{\circ} \mathrm{OH}\right)$, has attracted intensive research interest since the 1960s in the removal of a variety of recalcitrant organic contaminants. ${ }^{1}$ Typically, the Fenton process is conducted in a homogeneous way using dissolved ferrous ions and hydrogen peroxide as Fenton reagents. However, the application of the homogeneous Fenton process on an industrial scale is limited due to: (i) $\mathrm{pH}$-dependent chemical reactivity of iron; (ii) difficulty and complexity in separation and recovery of metal ions from the final effluent. ${ }^{2}$ Therefore, research efforts have been directed towards designing heterogeneous iron-based Fenton-like catalysts, such as iron oxide, ${ }^{3}$ iron exchanged zeolite ${ }^{4}$ and iron supported

Chemical and Metallurgical Engineering and Chemistry, School of Engineering and Information Technology, Murdoch University, Western Australia, Australia. E-mail: L.Li@murdoch.edu.au; Tel: +61893602569

$\dagger$ Electronic supplementary information (ESI) available: Kinetic parameters of pseudo-first-order and pseudo-second-order; UV-vis absorption spectra of the samples (the inset: the corresponding $[F(R) h \nu]^{2}$ versus $h \nu$ plots); change of RhB concentration in different systems: $\mathrm{RhB} /$ light, $\mathrm{RhB} / \mathrm{H}_{2} \mathrm{O}_{2}$ /light, RhB/HPS-0.15LFO/light, and RhB/HPS-0.15LFO/ $\mathrm{H}_{2} \mathrm{O}_{2} /$ dark; $\mathrm{pH}_{\mathrm{pzc}}$ of the HPS-0.15LFO sample using the pH drift method. See DOI: $10.1039 / \mathrm{c} 8 \mathrm{ra07073c}$ porous material. ${ }^{5}$ Combined with visible light irradiation, the cost-effectiveness of a heterogeneous Fenton-like process for use in wastewater treatment has been seen as promising. ${ }^{6,7}$

Perovskite materials having the generic formula of $\mathrm{ABO}_{3}$, in which A is typically an alkaline-earth or rare-earth element and $\mathrm{B}$ is a transition metal, have been found to exhibit high visible light photo-Fenton-like activity for dye degradation. ${ }^{8,9} \mathrm{Ju}$ et al. found that $\mathrm{EuFeO}_{3}$ nanoparticles prepared by the sol-gel method and calcined at $750{ }^{\circ} \mathrm{C}$ yielded $71 \%$ removal rate in $5 \mathrm{mg} \mathrm{\textrm {L } ^ { - 1 }}$ Rhodamine $\mathrm{B}(\mathrm{RhB})$ solution after being exposed to visible light for $3 \mathrm{~h}$, in the presence of $1 \mathrm{~g} \mathrm{~L}^{-1}$ catalyst and $0.05 \mathrm{~mL} \mathrm{H}_{2} \mathrm{O}_{2}{ }^{8}$ An and co-workers investigated the use of $\mathrm{BiFeO}_{3}$ heterogeneous photo-Fenton-like catalyst synthesized by the sol-gel method on the degradation of RhB, Methyl Violet (MV) and phenol. ${ }^{9}$ Their results revealed that with the assistance of visible light irradiation, the $\mathrm{RhB}$, phenol and $\mathrm{MV}$ degradation rate constant $(k)$, derived from the pseudo-firstorder model, was increased by 1.95, 2.07 and 3.47 times, respectively, compared to that under the dark condition. The utilization of visible light enhanced the photocatalytic activity of $\mathrm{BiFeO}_{3}$ for pollutant degradation in the presence of $\mathrm{H}_{2} \mathrm{O}_{2}$.

The literature suggests that $\mathrm{LaFeO}_{3}$ (LFO), as a member of the group of perovskite materials, could be a promising heterogeneous catalyst in the photo-Fenton degradation of pollutants. ${ }^{10-13}$ In the photo-Fenton reaction, the pollutant is believed to be oxidized and degraded by the attack of the hydroxyl radicals; thereby it is necessary to increase the number of active sites on the catalyst surface and in turn enhance the 
contact area between the pollutant and the catalyst towards the optimization of pollutant removal. However, LFO crystals synthesized via the traditional sol-gel method normally possess small specific surface area, show no porosity and therefore have a limited amount of active sites for catalytic degradation, ${ }^{\mathbf{1 0}, \mathbf{1 4}}$ due to the high temperature usually used in the synthesis.

So far, there has been some effort contributed to the development of supported LFO catalysts with porosity for highperformance Fenton or photo-Fenton degradation of pollutants. A number of materials have been explored for use as the supports, such as montmorillonite, ${ }^{15}$ carbon spheres, ${ }^{\mathbf{1 6}}$ mesoporous silicas, ${ }^{17,18}$ and graphene. ${ }^{19}$ In particular, mesoporous silicas have received recent research interest because of their unique features, including high specific surface area, tunable pore size and structure. ${ }^{20-23}$ Zhu's group successfully loaded LFO on SBA-15 mesoporous silica and investigated its Fentonlike catalytic activity for the oxidation of Rhodamine B (RhB), reactive brilliant red $\mathrm{X}-3 \mathrm{~B}$, direct scarlet $4 \mathrm{BS}$ and methylene blue (MB). ${ }^{17}$ The results showed that $80 \%$ and $66 \%$ of $\mathrm{RhB}$ and $\mathrm{MB}$ was removed after $60 \mathrm{~min}$, respectively; whilst that for 4BS and $\mathrm{X}-3 \mathrm{~B}$ was similar, approximately $42 \%$ (test conditions: $1 \mathrm{~mL}$ of $30 \mathrm{wt} \% \mathrm{H}_{2} \mathrm{O}_{2}, 0.1 \mathrm{~g}$ catalyst and $50 \mathrm{~mL}$ of $0.02 \mathrm{mmol} \mathrm{L}^{-1}$ dye solution). It was also concluded that SBA-15-supported LFO was more efficient than the bulk LFO in the catalysing oxidation of organic. Later the same group studied the role of silica, including porous (e.g. SBA-15, SBA-16, MCF) and non-porous silica powders, on RhB oxidative degradation using the supported LFO. ${ }^{24}$ Their results revealed that the LFO sample supported by MCF, which had randomly distributed pores and short pore length, exhibited the highest photocatalytic performance when compared to other LFO-doped samples. This suggests that the porous structure of the support plays an essential role in the adsorption of the organic, its transportation to active sites and eventually catalytic degradation. ${ }^{24}$ However, there have been few publications, exploring the use of silicasupported LFO for enhanced photo-Fenton degradation of organics under visible light irradiation. There have been no reports of studies to optimize its catalytic performance under different operational conditions or to investigate its feasibility for recycle and reuse; all of which is necessary information for practical utilization in wastewater treatment.

In this work, a type of mesoporous silica (HPS), which showed a unique fine pore system, narrow inner channels and wide outer pore opening, ${ }^{25}$ was selected as a support for different amounts of LFO doping to prepare heterogeneous photo-Fenton-like catalysts HPS- $x$ LFO (with theoretical LFO/ silica molar ratio $x=0.075,0.15,0.3)$. This unique mesoporous structure may endow great surface area for LFO doping and in turn would offer a large number of active sites. Meanwhile, its wider pore opening would greatly reduce the resistance to large organic molecules being transported into the pores and reaching active sites for catalytic degradation. RhB, a representative of xanthane dyes, is widely used in a variety of industries (e.g. textile, dyeing, paint and printing) and imposes hazardous effect on the environment and public health. ${ }^{26,27}$ Although significant effort has been concentrated on the application of methods, including adsorption, ${ }^{28}$ membrane separation, ${ }^{29}$ ion flotation ${ }^{30}$ and ozonation, ${ }^{31}$ to remove $\mathrm{RhB}$ from water, they have to date been found to be ineffective or uneconomical due to the stability of dye. ${ }^{26}$ In this study, we selected RhB as the model organic dye to investigate its removal effectiveness using HPS- $x$ LFO via adsorption and photo-Fenton catalytic degradation. The effect of catalyst dosage, $\mathrm{H}_{2} \mathrm{O}_{2}$ concentration, solution $\mathrm{pH}$ and co-existing ions on the photoFenton removal of RhB was investigated; and its performance after recycling was also studied.

\section{Experimental}

\subsection{Chemicals}

Cyclohexane $\left(\mathrm{C}_{6} \mathrm{H}_{12} ; 99.9 \%\right)$ 1-pentanol $\left(\mathrm{CH}_{3}\left(\mathrm{CH}_{2}\right)_{4} \mathrm{OH}\right.$; $\geq 99 \%$, cetyltrimethylammonium bromide $\left(\mathrm{CH}_{3}\left(\mathrm{CH}_{2}\right)_{15^{-}}\right.$ $\left.\mathrm{N}(\mathrm{Br})\left(\mathrm{CH}_{3}\right)_{3} ; 99 \%\right)$, tetraethyl orthosilicate $\left(\mathrm{Si}\left(\mathrm{OC}_{2} \mathrm{H}_{5}\right)_{4} ; 99 \%\right)$, lanthanum nitrate hexahydrate $\left(\mathrm{La}\left(\mathrm{NO}_{3}\right)_{3} \cdot 6 \mathrm{H}_{2} \mathrm{O} ; 99.9 \%\right)$, citric acid $\left(\mathrm{C}_{6} \mathrm{H}_{8} \mathrm{O}_{7} \cdot \mathrm{H}_{2} \mathrm{O} ; \geq 99.5 \%\right), \mathrm{H}_{2} \mathrm{O}_{2}(30 \mathrm{wt} \%)$, and Rhodamine $\mathrm{B}$ (RhB; $\geq 95 \%$ ) were purchased from Sigma-Aldrich. Iron nitrate nonahydrate $\left(\mathrm{Fe}\left(\mathrm{NO}_{3}\right)_{3} \cdot 9 \mathrm{H}_{2} \mathrm{O} ; 98-101 \%\right)$ was purchased from Alta Aesar. Urea $\left(\mathrm{NH}_{2} \mathrm{CONH}_{2}\right)$ was obtained from Merck Pty Limited, Australia. Other chemicals were from Biolab Ltd in Australia. All of the chemicals were used without additional purification.

\subsection{Preparation of porous silica}

Mesoporous silica (HPS-0LFO) support was synthesized according to a reported procedure. ${ }^{25}$ First of all, $2.7 \mathrm{~mL}$ tetraethyl orthosilicate (TEOS) was dissolved in the mixture with $1.5 \mathrm{~mL}$ 1-pentanol and $30 \mathrm{~mL}$ cyclohexane at the room temperature. The resulting solution was stirred for $5 \mathrm{~h}$, followed by the addition of a mixture which was made up of $1.87 \mathrm{~g}$ cetyltrimethylammonium bromide (CTAB), $0.6 \mathrm{~g}$ urea, $30 \mathrm{~mL}$ deionized (DI) water. After stirring, the solution was transferred into a Teflon-lined autoclave $(100 \mathrm{~mL})$ and heated in an oven at $120{ }^{\circ} \mathrm{C}$ for $4 \mathrm{~h}$. Finally, white precipitates were separated from the liquid, washed with acetone and DI water, dried in an oven and calcined in air at $550{ }^{\circ} \mathrm{C}$ for $6 \mathrm{~h}$ (heating rate of $1{ }^{\circ} \mathrm{C} \mathrm{min}{ }^{-1}$ from room temperature to $550{ }^{\circ} \mathrm{C}$ ).

\subsection{Synthesis of $\mathrm{LaFeO}_{3}$-doped HPS}

$\mathrm{LaFeO}_{3}$-doped mesoporous silica (HPS- $x$ LFO) was synthesized by impregnation and subsequent calcination. Typically, $10 \mathrm{mmol} \mathrm{La}\left(\mathrm{NO}_{3}\right)_{3} \cdot 6 \mathrm{H}_{2} \mathrm{O}, 10 \mathrm{mmol} \mathrm{Fe}\left(\mathrm{NO}_{3}\right)_{3} \cdot 9 \mathrm{H}_{2} \mathrm{O}$ and $20 \mathrm{mmol}$ citric acid was dissolved in a mixture of $10 \mathrm{~mL}$ DI water and $20 \mathrm{~mL}$ of ethanol to form a homogeneous solution at room temperature. After adding $2 \mathrm{~g}$ HPS-0LFO, the resulting suspension was stirred at room temperature for $3 \mathrm{~h}$ and then at $70{ }^{\circ} \mathrm{C}$ to evaporate the solvent, followed by drying at $80^{\circ} \mathrm{C}$ and then calcination at $700{ }^{\circ} \mathrm{C}$ (heating rate of $2{ }^{\circ} \mathrm{C} \mathrm{min}^{-1}$ from room temperature to $700{ }^{\circ} \mathrm{C}$ ). The theoretical molar ratio between $\mathrm{LaFeO}_{3}$ (LFO) and silica in different samples was 0.075, 0.15 and 0.3 . The corresponding catalysts were designated as HPS-0.075LFO, HPS-0.15LFO, and HPS-0.3LFO, respectively. For comparison, the sample, which was synthesized following 
the same above procedures in the absence of HPS, was denoted as LFO.

\subsection{Sample characterization}

Powder X-ray diffraction (XRD) measurement was performed on a diffractometer (XRD, GBC eMMA), which was operated in the reflection mode with $\mathrm{Cu} \mathrm{K} \alpha$ radiation $(28 \mathrm{~mA}, 35 \mathrm{kV})$ at a step size of $1^{\circ} \mathrm{min}^{-1}$ in the range of $10-80^{\circ}$. The surface morphology and elemental composition of each sample was characterized using Scanning Electron Microscopy (SEM) (Zeiss 1555, VPFESEM) at an accelerating voltage of $5 \mathrm{kV}$ with energy dispersive X-ray spectrometry (EDS). The samples were loaded onto the carbon tape and coated by platinum. Transmission Electron Microscopy (TEM) analysis was performed on TEM-TITAN operating at $200 \mathrm{kV}$. The samples were dispersed in ethanol under ultrasonication and loaded onto carbon copper grid for TEM characterization. Nitrogen adsorption-desorption isotherms were measured at $77 \mathrm{~K}$ using SAPA2010 (Micromeritics Inc., USA). The samples were degassed at $200{ }^{\circ} \mathrm{C}$ overnight under vacuum.

\subsection{Removal of $\mathrm{RhB}$ from water}

$100 \mathrm{~mL}$ of $\mathrm{RhB}$ aqueous solution $\left(10 \mathrm{mg} \mathrm{L}^{-1}\right)$ was introduced into a cylindrical Pyrex vessel $(300 \mathrm{~mL})$, surrounded by a circulating water jacket to maintain solution temperature at $25{ }^{\circ} \mathrm{C} .100 \mathrm{mg}$ of HPS- $x$ LFO $(x=0,0.075,0.15,0.3)$ or $100 \mathrm{mg}$ of LFO was added to the RhB solution; the resulting suspension was magnetically stirred in the dark for $90 \mathrm{~min}$ to investigate its adsorption of RhB in water. Samples were taken from the suspension at given period of times and centrifuged at $10000 \mathrm{rpm}$. The obtained supernatant was analysed using a Perkin Elmer Lambda 750 UV/Vis spectrometer to determine the concentration of $\operatorname{RhB}\left(C_{\mathrm{i}}, \mathrm{mg} \mathrm{L}^{-1}\right)$, compared to the initial concentration of $\mathrm{RhB}$ before adsorption $\left(C, \mathrm{mg} \mathrm{L}^{-1}\right)$.

The results showed that the adsorption-desorption equilibrium was achieved within $30 \mathrm{~min}$. Therefore, the photoFenton catalytic degradation test was started after $30 \mathrm{~min}$ dark adsorption using the catalyst. Typically, $100 \mathrm{~mL}$ of RhB aqueous solution $\left(10 \mathrm{mg} \mathrm{L^{-1 }}\right)$ was introduced into a cylindrical Pyrex vessel $(300 \mathrm{~mL})$, surrounded by a circulating water jacket to maintain solution temperature at $25{ }^{\circ} \mathrm{C}$. $100 \mathrm{mg}$ of HPS- $x$ LFO $(x=0,0.075,0.15,0.3)$ or LFO was added to the RhB solution; the resulting suspension was magnetically stirred in the dark for $30 \mathrm{~min}$ to reach adsorptiondesorption equilibrium. After that, a xenon lamp (CEL-HX F300) with a $400 \mathrm{~nm}$ cut-off filter was used to provide visible light and $1 \mathrm{~mL} \mathrm{H}_{2} \mathrm{O}_{2}$ was added to the suspension to initiate the photo-Fenton-like reaction. Samples were taken from the suspension at given periods of time and centrifuged at $10000 \mathrm{rpm}$. The obtained supernatant was analysed using Perkin Elmer Lambda $750 \mathrm{UV} / \mathrm{Vis}$ spectrometer to determine the concentration of $\mathrm{RhB}\left(C_{t}, \mathrm{mg} \mathrm{L}^{-1}\right)$, as compared with the concentration of $\mathrm{RhB}$ before starting photo-Fenton-like degradation $\left(C_{0}, \mathrm{mg} \mathrm{L}^{-1}\right)$.
The reusability of the catalyst was assessed by repeating the photo-Fenton degradation test under the same reaction conditions after recovering HPS-0.15LFO from the solution.

\section{Results and discussion}

\subsection{Characterization of HPS- $x$ LFO}

The general morphologies of HPS- $x$ LFO $(x=0,0.075,0.15,0.3)$ with different LFO loadings are presented in Fig. 1. The sample of HPS-0LFO exhibited monodispersed spheres with a particle diameter of $\sim 300-400 \mathrm{~nm}$. The morphology of LFO-loaded HPS (HPS-0.075LFO, HPS-0.15LFO, and HPS-0.3LFO) was similar to that of HPS-0LFO, suggesting that the HPS support is stable during doping with LFO. No significant LFO crystals or clumps were seen separately from the particles of HPS- $x$ LFO $(x=0.075$, $0.15,0.3)$.

The morphology and size of HPS and HPS-0.15LFO observed by TEM (Fig. 2a and b) are consistent with those in Fig. 1. In Fig. 2a, the particles of HPS-0LFO exhibited a unique mesoporous structure. Compared with Fig. 2a, the TEM image of HPS-0.15LFO (Fig. 2b) shows that some small particles (e.g.

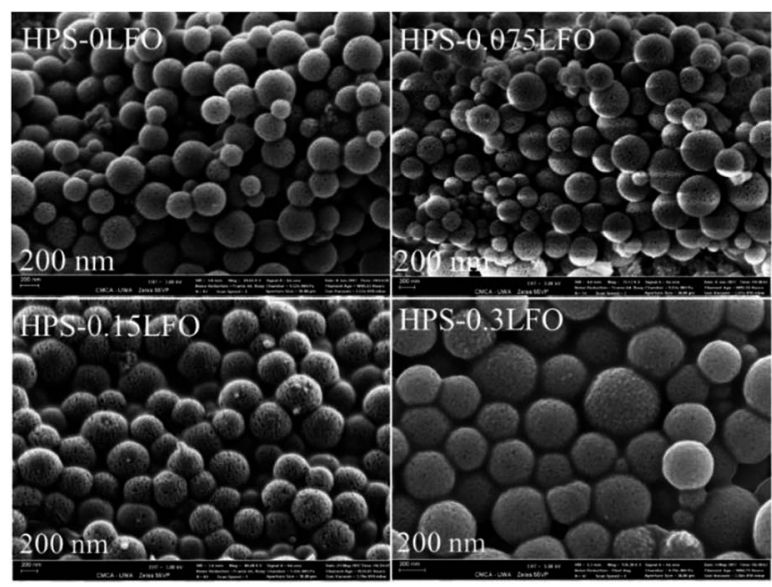

Fig. 1 SEM images of HPS- $x$ LFO $(x=0,0.075,0.15,0.3)$ samples.

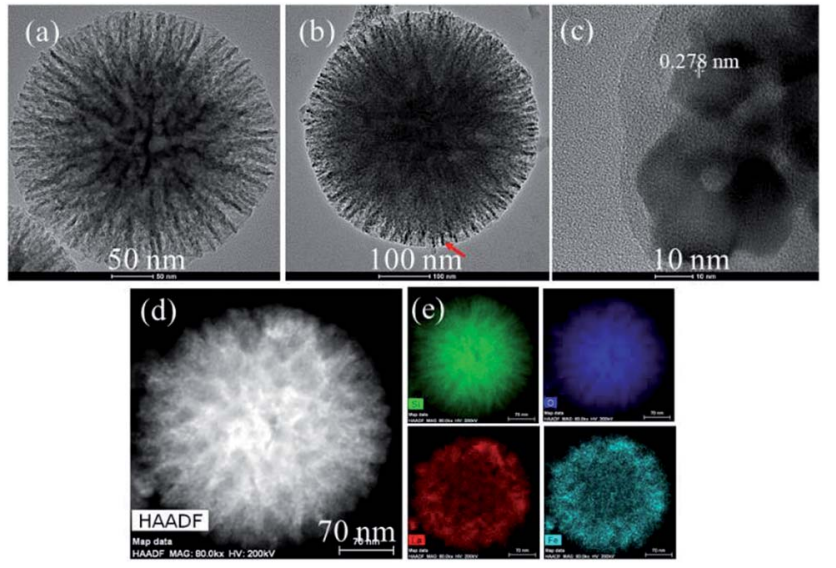

Fig. 2 TEM images of (a) HPS-OLFO and (b) HPS-0.15LFO; (c) HRTEM image of HPS-0.15LFO; (d) HAADF scanning TEM image of HPS-0.15LFO and (e) the corresponding elemental mapping (Si, O, La, and Fe). 
indicated in red) were loaded in the HPS support. These particles were observed with an interplanar distance of $0.278 \mathrm{~nm}$ (Fig. 2c), which corresponds to the (121) crystal plane of LFO. ${ }^{32}$ The high-angle-annular dark-field (HAADF) scanning TEM image of HPS-0.15LFO (Fig. 2d), and the corresponding elemental mapping images (Fig. 2e) further confirm that LFO was loaded to the HPS support.

The XRD patterns of HPS- $x$ LFO $(x=0,0.075,0.15,0.3)$ are shown in Fig. 3 ; the XRD pattern of LFO synthesized without the use of HPS was included for comparison. A broad characteristic peak at $2 \theta=23^{\circ}$ was observed for the amorphous mesoporous $\mathrm{SiO}_{2}$, HPS-0LFO. As expected, the LFO loading affected the porous structure of the HPS support. The characteristic peak intensity of $\mathrm{SiO}_{2}$ considerably decreased with increased LFO loading in HPS, which is probably due to the partial or complete filling of LFO inside the HPS pores. The samples of HPS0.075LFO, HPS-0.15LFO, and HPS-0.3LFO exhibited the characteristic diffraction peaks indexable to the orthorhombic structure of LFO (JCPDS no. 37-1493). ${ }^{33}$ No apparent characteristic peaks of impurities were detected, confirming the high purity of the samples.

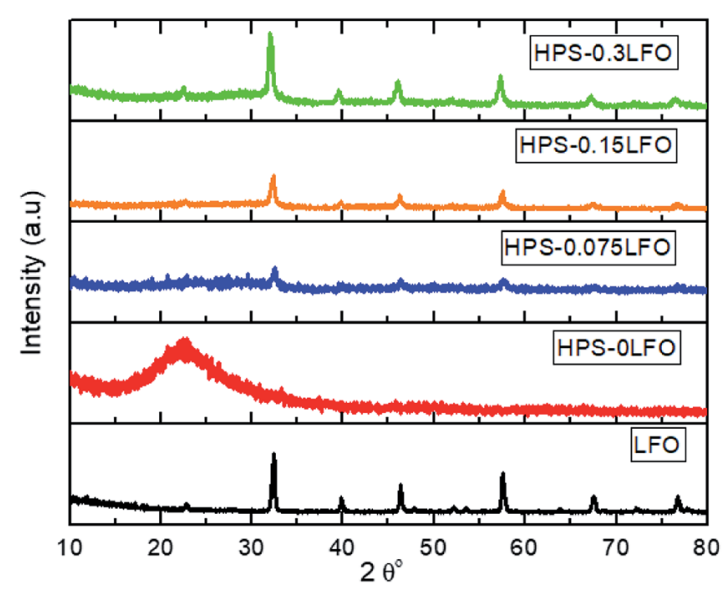

Fig. 3 XRD patterns of HPS- $x$ LFO $(x=0,0.075,0.15,0.3)$ as compared with that of LFO.

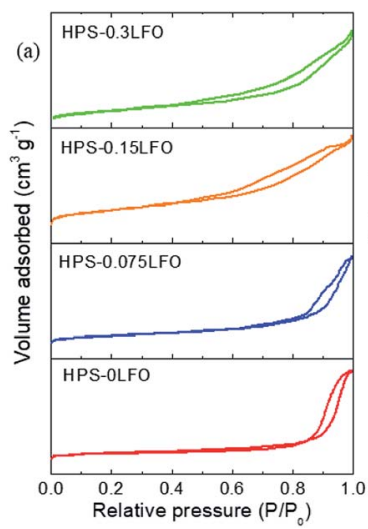

(b)

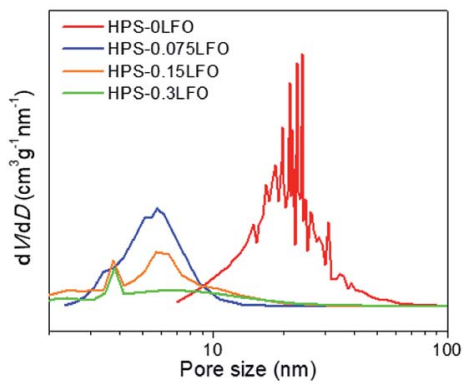

Fig. 4 (a) $\mathrm{N}_{2}$ adsorption-desorption isotherms and (b) BJH pore size distributions of HPS- $x$ LFO $(x=0,0.075,0.15,0.3)$.
The nitrogen adsorption-desorption isotherms and $\mathrm{BJH}$ pore size distribution curves of HPS- $x$ LFO $(x=0,0.075,0.15$, 0.3) are shown in Fig. 4. The $\mathrm{N}_{2}$ adsorption-desorption isotherm curves of all samples showed a type IV isotherm with H2-hysteresis loops (Fig. 4a), which suggests the characteristic of mesoporous structure. ${ }^{25}$ It can be seen from Fig. $4 \mathrm{~b}$ that HPS possessed a broad pore size distribution with multimodal mesopores ranging from $15 \mathrm{~nm}$ to $30 \mathrm{~nm}$. It is worth noting that the high BET surface area of $496.62 \mathrm{~m}^{2} \mathrm{~g}^{-1}$ was recorded for HPS-0LFO; whereas that of HPS- $x$ LFO $(x=0.075,0.15,0.3)$ was considerably reduced from $349.52 \mathrm{~m}^{2} \mathrm{~g}^{-1}$ to $123.12 \mathrm{~m}^{2} \mathrm{~g}^{-1}$ as the theoretical molar ratio of LFO loading to silica increased from 0.075 to 0.3 . The pore volume of HPS- $x$ LFO showed a similar trend, from $2.34 \mathrm{~cm}^{3} \mathrm{~g}^{-1}$ (HPS-0LFO), $1.22 \mathrm{~cm}^{3} \mathrm{~g}^{-1}$ (HPS-0.075LFO), $0.47 \mathrm{~cm}^{3} \mathrm{~g}^{-1}$ (HPS-0.15LFO) to $0.27 \mathrm{~cm}^{3} \mathrm{~g}^{-1}$ (HPS-0.3LFO). The decrease of BET surface area and total pore volume accompanied with the increase of LFO loading could be attributed to the presence of LFO in the pores and channels of the HPS support. These results suggest that LFO was successfully incorporated into the mesopores of HPS. A low BET surface area of $8.06 \mathrm{~m}^{2} \mathrm{~g}^{-1}$ was observed for the LFO sample synthesized without the use of a HPS support. As can be seen, the LFOdoped HPS samples exhibited much higher specific surface area and presented accessible pores, providing more active sites and pathways for RhB removal.

Fig. S1 $\uparrow$ presents the UV-vis absorption spectra of HPS-doped LFO as compared with that of LFO. All samples exhibited the broad absorption peaks in the visible region, implying they could absorb visible light. Fig. 5 presents the bandgap values of LFO and HPS- $x$ LFO $(x=0.075,0.15,0.3)$. They were estimated from the interception of the straight line fitted the curve $[F(R) h \nu]^{2}$ versus $h \nu$, in which $F(R)$ is the Kubelka-Munk function and $h \nu$ is the energy of the incident photon (shown in the inset of Fig. S1†). The corresponding bandgap was $2.21 \mathrm{eV}, 2.31 \mathrm{eV}$, and $2.34 \mathrm{eV}$, respectively, for HPS-0.075LFO, HPS-0.15LFO, HPS-0.3LFO, which was narrower as compared with $2.36 \mathrm{eV}$ for LFO. In the literature, Perathoner and co-workers also reported the improved effectiveness of light absorption of SBA15-supported $\mathrm{TiO}_{2}$, relative to $\mathrm{TiO}_{2} \cdot{ }^{34}$

\subsection{Adsorptive removal of RhB using HPS- $x$ LFO}

The photo-Fenton degradation of RhB generally takes place on the surface of catalyst; therefore the RhB adsorption capability of

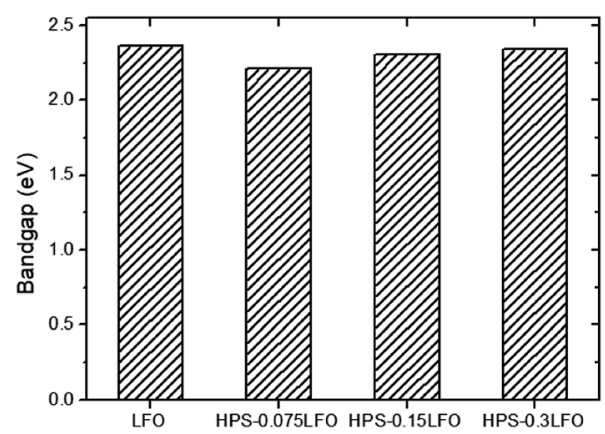

Fig. 5 Bandgap of HPS- $x$ LFO $(x=0.075,0.15,0.3)$, as compared with that of LFO. 

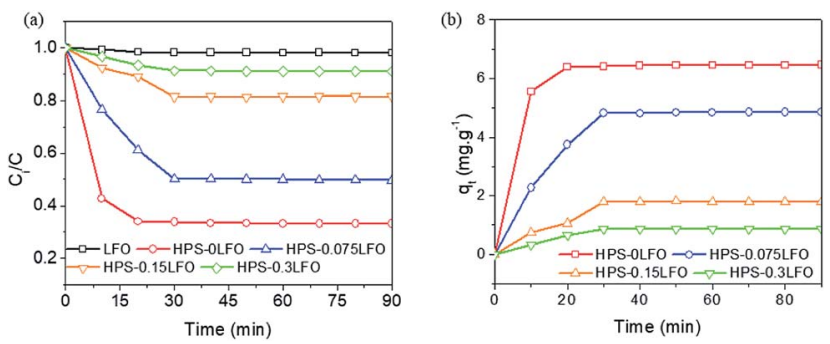

Fig. 6 (a) Removal of RhB via adsorption by using LFO or HPS- $x$ LFO ( $x$ $=0,0.075,0.15,0.3$ ) (reaction conditions: temperature $=25^{\circ} \mathrm{C}$; initial $\mathrm{RhB}$ concentration $=10 \mathrm{mg} \mathrm{L}^{-1}$; catalyst dosage $\left.=1 \mathrm{~g} \mathrm{~L}^{-1} ; \mathrm{pH}=6\right)$; (b) the corresponding RhB adsorption capacity.

LFO or HPS- $x$ LFO $(x=0,0.075,0.15,0.3)$ is expected to affect its photocatalytic performance. ${ }^{24,35-37}$ Fig. 6 a shows the adsorptive removal of RhB using LFO and HPS- $x$ LFO $(x=0,0.075,0.15,0.3)$, which was conducted in the dark for $90 \mathrm{~min}$. Fig. $6 \mathrm{~b}$ reveals the $\mathrm{RhB}$ adsorption capacity of the samples as a function of time.

The adsorption kinetics were not in good agreement with the pseudo-first-order model, as revealed by the low values of $r^{2}\left(r^{2}\right.$ $=0.8161-0.9862)$ in Table S1. $\dagger$ On the other side, high correlation coefficients $\left(r^{2}=0.9661-0.9998\right.$; Table $\left.\mathrm{S} 1 \dagger\right)$ of the linear plots suggest the good agreement of the kinetic data with the pseudo-second-order model, which indicates the process is mainly chemisorption.

As shown above, the HPS- $x$ LFO $(x=0,0.075,0.15,0.3)$ samples exhibited better adsorption capability of RhB than LFO. This might be ascribed to their structural properties (specific surface area and porosity), which were seen in the SEM, TEM and nitrogen adsorption-desorption characterization. The porous structure of the HPS support (HPS-0LFO) was observed in the SEM and TEM images (Fig. 1 and 2), which could offer more space and pathways to facilitate the adsorption of RhB as compared with LFO solid crystals. Moreover, mesoporous silica material has an abundance of silanol groups ( $\mathrm{Si}-\mathrm{OH})$ on the surface ${ }^{38,39}$ whilst RhB molecules contain carboxyl groups. A hydrogen bond might be established between the functional groups of the HPS support and $\mathrm{RhB},{ }^{\mathbf{4 0}}$ which would translate into higher RhB adsorption by HPS- $x$ LFO than by LFO. HPSOLFO exhibited the highest adsorption capacity as compared to other LFO-doped HPS samples (HPS-0.075LFO, HPS-0.15LFO and HPS-0.3LFO); since the doping of LFO into the HPS support reduced specific surface area, pore volume and number of surface silanol groups. The BET surface area and pore volume of the catalysts changed in a trend of HPS-0LFO $>$ HPS-0.075LFO > HPS-0.15LFO > HPS-0.3LFO. This is consistent with the obtained results for RhB adsorption capability.

\subsection{Photo-Fenton catalytic degradation of RhB using HPS- $x$ LFO}

To evaluate the photo-Fenton-like catalytic activity of HPS- $x$ LFO $(x=0,0.075,0.15,0.3)$, the degradation of RhB in the presence of $\mathrm{H}_{2} \mathrm{O}_{2}$ under visible light irradiation was carried out. The data were fitted with the pseudo-first-order kinetic model and the apparent rate constant was obtained from the slope of the straight line by plotting $-\ln \left(C_{t} / C_{0}\right)$ as a function of time.
Fig. $\mathrm{S} 2 \uparrow$ reveals no change in $C_{t} / C_{0}$ in the absence of catalyst and $\mathrm{H}_{2} \mathrm{O}_{2}$, implying that $\mathrm{RhB}$ does not be self decompose under visible light irradiation. Without the use of catalyst, approximately $7 \%$ of $\mathrm{RhB}$ was removed in the presence of $\mathrm{H}_{2} \mathrm{O}_{2}$ and visible light. A limited amount of $\mathrm{RhB}(\sim 5 \%)$ was removed using just the catalyst of HPS-0.15LFO and exposure to visible light source. As compared with the results in Fig. 7, the use of $\mathrm{H}_{2} \mathrm{O}_{2}$ is indispensible for the efficient removal of $\mathrm{RhB}$ from water when using the as-prepared catalyst herein.

The photo-Fenton-like catalytic degradation of RhB using HPS$0.075 \mathrm{LFO}$ was $72.1 \%$, which was slightly lower than that using LFO, which was $88.6 \%$. The pseudo-first-order reaction constant of HPS-0.075LFO and HPS-0LFO was $0.0174 \mathrm{~min}^{-1}$ and $0.0215 \mathrm{~min}^{-1}$, respectively. The relatively lower degradation performance of HPS-0.075LFO might be explained by the small loading of LFO into the HPS support resulting in fewer active sites available for degradation. When the molar ratio of LFO loading and silica was increased to 0.15 the RhB degradation efficiency of HPS-0.15LFO reached $97.5 \%$, with the pseudo-first-order reaction rate constant $0.0423 \mathrm{~min}^{-1}$. However, when using HPS-0.3LFO, the degradation efficiency was reduced slightly to $95.9 \%$ (the pseudofirst-order reaction rate constant was $0.0327 \mathrm{~min}^{-1}$ ). This could be attributed to excess LFO partially covering or blocking the pores in the HPS support; as a result, the transport of organic into pores and subsequently its degradation was hindered.

Note that, the use of HPS-0.15LFO and HPS-0.3LFO resulted in better removal of $\mathrm{RhB}$ (97.5\% and $95.9 \%$, respectively) than LFO $(88.6 \%)$ in the photo-Fenton degradation. In particular, the theoretical molar ratio of LFO/silica in HPS-0.15LFO and HPS$0.3 \mathrm{LFO}$ was 0.15 and 0.3. No degradation of RhB was found when using the HPS support (HPS-0LFO) as the catalyst, suggesting the support plays no role in degradation reaction. That implies that for the same dosage of catalyst, the actual amount of LFO in the doped HPS participating in the reaction was much smaller but its activity was more efficient, as compared with the bulk LFO crystals. On the other side, the RhB adsorption using HPS-0.15LFO or HPS-0.3LFO was noticeable in Fig. 6, in contrast to the negligible adsorption using the bulk LFO crystals. This suggests that both of the LFO-doped catalysts could adsorb RhB from solution onto the silica support and guarantee the degradation to occur smoothly on the LFO active sites. ${ }^{24}$

As can be seen above, the plain silica support HPS-0LFO could remove $\mathrm{RhB}$ to some level, mainly governed by
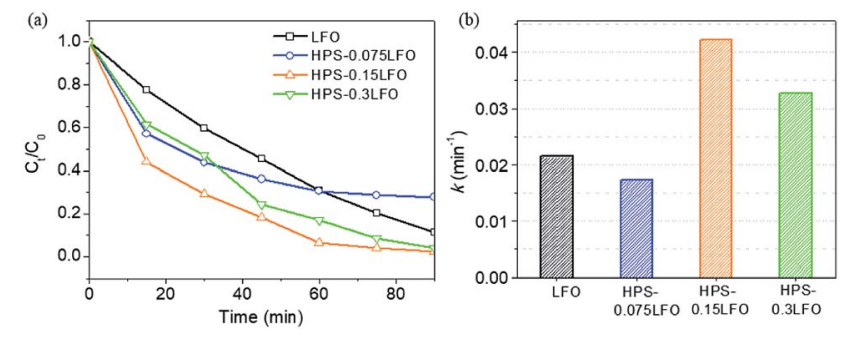

Fig. 7 (a) Removal of RhB in the photo-Fenton reaction using LFO or HPS- $x$ LFO ( $x=0.075,0.15$, and 0.3$)$ and (b) corresponding degradation rate constants (reaction conditions: temperature $=25{ }^{\circ} \mathrm{C}$, initial dye concentration $=10 \mathrm{mg} \mathrm{L}^{-1}$, catalyst dosage $=1 \mathrm{~g} \mathrm{~L}^{-1}$, initial $\mathrm{H}_{2} \mathrm{O}_{2}$ concentration $=10 \mathrm{mM}$ and initial $\mathrm{pH}=6$ ). 
adsorption ( $\sim 65 \%$ shown in Fig. $6 a)$. So far, various methods, including biological, physical and chemical ways, have been widely explored to remove organics and dyes from water. Adsorption, as a traditional method, only transfers dyes from water to another phase. It normally requires further treatment of saturated adsorbents after adsorption, e.g. disposal or regeneration. For example, in the case of this study, the use of high temperature (normally $>500{ }^{\circ} \mathrm{C}$ ) or organic solvent would be needed to regenerate dye-saturated adsorbents for recycle and reuse, ${ }^{\mathbf{4 1 , 4 2}}$ which may add further cost and complexity to the process. Advanced oxidation process (AOPs) have shown advantageous features as compared with adsorption. Especially, the heterogenous AOPs (e.g. photo-Fenton) has demonstrated promising results for degradation of dyes to produce more biologically degradable and less toxic substances. ${ }^{43}$ In our study, the use of LFO doping onto HPS (e.g. HPS-0.15LFO) could achieve much better total removal rate of $\mathrm{RhB}$ (over 98\%), as compared to only $<75 \%$ using the parent HPS-0LFO. Note that, the regeneration process herein is simple and capable for scaleup; especially it required no high temperature calcination and organic solvent (the results of recycle and reuse were shown in 3.4.5). The photo-Fenton catalytic performance in terms of dye removal using HPS-0.15LFO was almost completely retained after 4 cycles of use.

Our work also compared the photo-Fenton catalytic performance of HPS-0.15LFO with that of $\mathrm{Fe}_{2} \mathrm{O}_{3}$-doped HPS using our HPS support (under the same molar ratio of loading). However, the preliminary results found that the degradation rate of plain $\mathrm{Fe}_{2} \mathrm{O}_{3}$ or its doped HPS was $<70 \%$, thus lower than that of HPS0.15 LFO. More systematic study is undertaken to reveal the reasons.

As discussed above, HPS-0.15LFO exhibited the greatest reaction rate constant, best degradation performance and highest removal efficiency, among the samples of LFO-doped HPS, HPS support and LFO pure crystals. Therefore, we selected HPS-0.15LFO to study the effects of catalyst dosage, $\mathrm{H}_{2} \mathrm{O}_{2}$ centration, initial $\mathrm{pH}$ and co-existing ions on photoFenton degradation of RhB.

Interestingly, in the dark, HPS-0.15LFO yielded a degradation rate of $66.5 \%$ (Fig. $\mathrm{S} 2 \dagger$ ), revealing that HPS-0.15LFO can act as a heterogeneous Fenton-like catalyst. ${ }^{24}$ With the use of visible light, the degradation of RhB was significantly enhanced, up to $97.5 \%$, strongly suggesting that the combination of HPS$0.15 \mathrm{LFO}$ catalyst, $\mathrm{H}_{2} \mathrm{O}_{2}$ and visible light is necessary to achieve efficient and effective removal of RhB.

\subsection{Effect of operational parameters on photo-Fenton using HPS-0.15LFO}

3.4.1 Effect of catalyst dosage. The impact of HPS-0.15LFO dosage on the RhB degradation was assessed in Fig. 8a. The increase of HPS-0.15LFO dosage from $0.5 \mathrm{~g} \mathrm{~L}^{-1}$ to $1.0 \mathrm{~g} \mathrm{~L}^{-1}$ led to the enhancement of degradation from $94.8 \%$ to $97.5 \%$; whereas the degradation efficiency decreased to $96.1 \%$ when further increasing HPS-0.15LFO dosage up to $1.2 \mathrm{~g} \mathrm{~L}^{-1}$. As can be seen clearly from Fig. $8 \mathrm{~b}$ that the pseudo-first-order reaction rate constant $k$ at different dosages followed the order: $0.5 \mathrm{~g} \mathrm{~L}^{-1}$
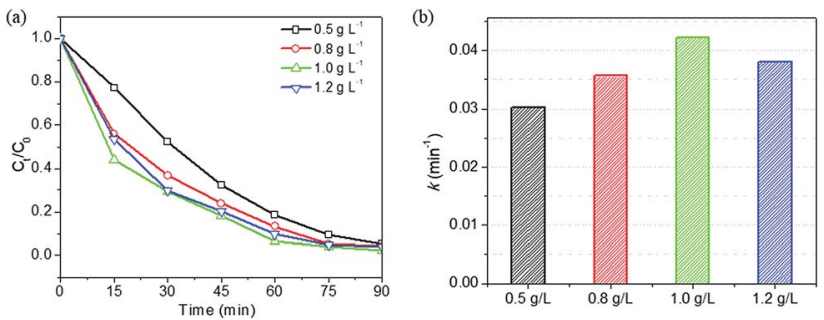

Fig. 8 (a) Effect of catalyst dosage on the removal of RhB in the photo-Fenton reaction and (b) degradation rate constants (reaction conditions: temperature $=25{ }^{\circ} \mathrm{C}$, initial dye concentration $=$ $10 \mathrm{mg} \mathrm{L}^{-1}$, initial $\mathrm{H}_{2} \mathrm{O}_{2}$ concentration $=10 \mathrm{mM}$ and initial $\mathrm{pH}=6$ ).

$<0.8 \mathrm{~g} \mathrm{~L}^{-1}<1.2 \mathrm{~g} \mathrm{~L}^{-1}<1 \mathrm{~g} \mathrm{~L}^{-1}$. This can be explained by the increasing number of active sites for $\mathrm{RhB}$ degradation. However, further increase of catalyst dosage may limit the visible light transmission into the reaction suspension, and in turn lower visible light utilization and reduce photo-Fenton degradation efficiency. Therefore, $1 \mathrm{~g} \mathrm{~L}^{-1}$ was identified as the optimal catalyst dosage for photo-Fenton degradation of RhB using HPS-0.15LFO in our experiment.

3.4.2 Effect of $\mathrm{H}_{2} \mathrm{O}_{2}$ concentration. In the photo-Fentonlike catalytic degradation, $\mathrm{H}_{2} \mathrm{O}_{2}$ concentration has a great influence on the degradation of organic pollutants due to the fact that the amount of generated ${ }^{\circ} \mathrm{OH}$ radicals is governed by the concentration of $\mathrm{H}_{2} \mathrm{O}_{2} \cdot{ }^{44}$ The photo-Fenton catalytic degradation of RhB using HPS-0.15LFO in the presence of various concentrations of $\mathrm{H}_{2} \mathrm{O}_{2}$ is presented in Fig. 9a. It was observed that as the $\mathrm{H}_{2} \mathrm{O}_{2}$ concentration increased from $10 \mathrm{mM}$ to $15 \mathrm{mM}$, the degradation efficiency of $\mathrm{RhB}$ was enhanced, reaching to $98.6 \%$. However, further increase in $\mathrm{H}_{2} \mathrm{O}_{2}$ concentration did not considerably improve the degradation efficiency. The RhB degradation efficiency was $97.9 \%$ for the $\mathrm{H}_{2} \mathrm{O}_{2}$ concentration was $20 \mathrm{mM}$ and this rate then decreased to $95.7 \%$ when increasing the $\mathrm{H}_{2} \mathrm{O}_{2}$ concentration up to $25 \mathrm{mM}$. The fittings of photo-Fenton catalytic degradation data in Fig. 9b illustrate that the pseudo-first-order reaction rate constants $k$ for RhB degradation in $10 \mathrm{mM}, 15 \mathrm{mM}, 20 \mathrm{mM}$, and $25 \mathrm{mM}$ $\mathrm{H}_{2} \mathrm{O}_{2}$ were $0.0423 \mathrm{~min}^{-1}, 0.0544 \mathrm{~min}^{-1}, 0.0486 \mathrm{~min}^{-1}$, and $0.0380 \mathrm{~min}^{-1}$, respectively.

It might be attributed to the scavenging effect because of excess $\mathrm{H}_{2} \mathrm{O}_{2}$, as shown in eqn (1): ${ }^{45}$
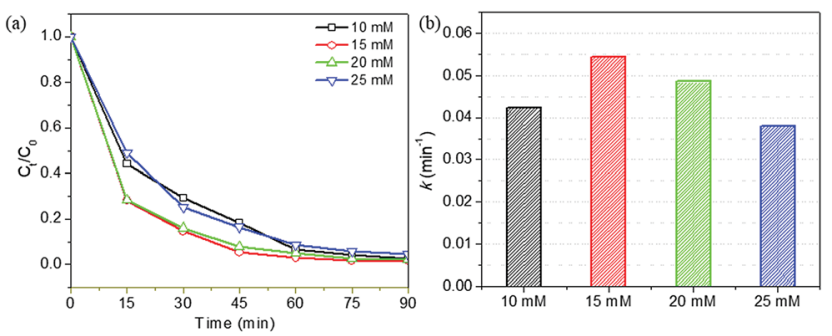

Fig. 9 (a) Effect of $\mathrm{H}_{2} \mathrm{O}_{2}$ on the removal of $\mathrm{RhB}$ in the photo-Fenton reaction and (b) degradation rate constants (reaction conditions: temperature $=25^{\circ} \mathrm{C}$, initial dye concentration $=10 \mathrm{mg} \mathrm{L}^{-1}$, catalyst dosage $=1 \mathrm{~g} \mathrm{~L}^{-1}$ and initial $\mathrm{pH}=6$ ). 


$$
\mathrm{H}_{2} \mathrm{O}_{2}+{ }^{\cdot} \mathrm{OH} \rightarrow \mathrm{HO}_{2} \cdot+\mathrm{H}_{2} \mathrm{O}
$$

At high concentration of $\mathrm{H}_{2} \mathrm{O}_{2}, \mathrm{H}_{2} \mathrm{O}_{2}$ could act as a ${ }^{\circ} \mathrm{OH}$ radical scavenger, resulting in the reduced number of ${ }^{\circ} \mathrm{OH}$ radicals. Moreover, the generated $\mathrm{HO}_{2}{ }^{\cdot}$ would be less reactive than ${ }^{\circ} \mathrm{OH} ;{ }^{46}$ as a result, the $\mathrm{RhB}$ degradation efficiency decreased. The optimal $\mathrm{H}_{2} \mathrm{O}_{2}$ concentration for the photoFenton degradation of RhB using HPS-0.15LFO was found to be $15 \mathrm{mM}$.

3.4.3 Effect of initial $\mathbf{p H}$. The effect of initial solution $\mathrm{pH}$ on the degradation of RhB is presented in Fig. 10a. The experiment was conducted in the $\mathrm{pH}$ range of $4-9$. Since textile industry wastewater is nearly neutral to slightly acidic, ${ }^{47}$ the optimal $\mathrm{pH}$ in the photo-Fenton-like degradation of $\mathrm{RhB}$ using HPS-0.15LFO is of importance to determine cost effectiveness of process.

As reported in the literature, ${ }^{48,49}$ the low degradation\% of $\mathrm{RhB}$ at high $\mathrm{pH}$ might be attributed to the decomposition of $\mathrm{H}_{2} \mathrm{O}_{2}$ into less reactive hydroperoxyl radicals and the restriction of ${ }^{\circ} \mathrm{OH}$ production in a basic medium. Moreover, in a solution with $\mathrm{pH}>3.7$ ( $\mathrm{p} K_{\mathrm{a}}$ of $\left.\mathrm{RhB}\right), \mathrm{RhB}$ presents in zwitterionic form. ${ }^{26}$ At high $\mathrm{pH}$, the zwitterionic form of $\mathrm{RhB}$ tends to form bigger molecules ${ }^{50}$ which might hinder the transport and entry of dye molecules into the pores of HPS-15LFO. In addition, the zwitterionic form of $\mathrm{RhB}$ molecules at high $\mathrm{pH}$ are less attackable by OH radicals. ${ }^{26}$ These effects could explain the decrease in the degradation of $\mathrm{RhB}$ which was observed at high $\mathrm{pH}(e . g . \mathrm{pH}>6)$. Fig. 10b shows that the pseudo-first-order reaction rate constant $k$ was the highest $\left(0.0544 \mathrm{~min}^{-1}\right)$ at $\mathrm{pH}=6$; as compared with $0.0404 \mathrm{~min}^{-1}, 0.0346 \mathrm{~min}^{-1}$ and $0.0287 \mathrm{~min}^{-1}$ at $\mathrm{pH}=7,8$ and 9, respectively. The maximum degradation efficiency of $\mathrm{RhB}$ (98.6\%) was observed at $\mathrm{pH}=6$.

Note that the RhB degradation rate gradually decreased as the initial solution $\mathrm{pH}$ was reduced from 6 down to 4 . Fig. 10b shows that the pseudo-first-order reaction rate constant $k$ was $0.0369 \mathrm{~min}^{-1}$ and $0.0437 \mathrm{~min}^{-1}$, respectively at $\mathrm{pH}=4$ and 5 ; which was smaller than that at $\mathrm{pH}=6\left(0.0544 \mathrm{~min}^{-1}\right)$, but still comparable or greater than those at $\mathrm{pH}>6$. Fig. $\mathrm{S} 3 \dagger$ reveals the $\mathrm{pH}_{\mathrm{pzc}}$ of HPS-15LFO to be 6.39, using pH drift method. ${ }^{51-53}$ When the solution $\mathrm{pH}$ was below the $\mathrm{pH}_{\mathrm{pzc}}$, the surface of HPS$15 \mathrm{LFO}$ was positively charged; and above the $\mathrm{pH}_{\mathrm{pzc}}$, the surface was negatively charged. As the proton concentration increased at lower $\mathrm{pH}, \mathrm{RhB}$ could be protonated to $\mathrm{RhBH}^{+}$under the
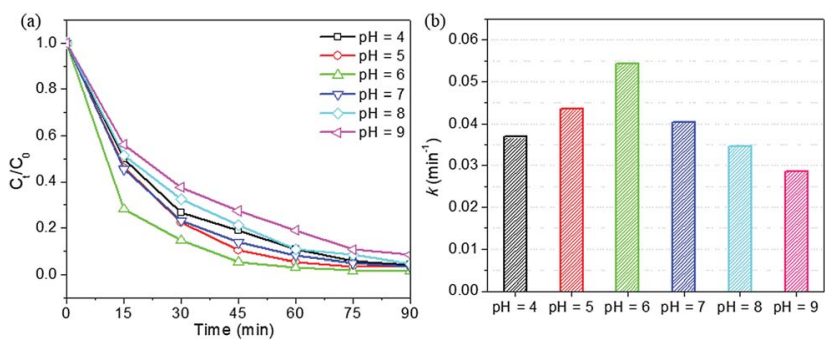

Fig. 10 (a) Effect of initial solution $\mathrm{pH}$ on the removal of $\mathrm{RhB}$ in the photo-Fenton reaction and (b) degradation rate constants (reaction conditions: temperature $=25{ }^{\circ} \mathrm{C}$, initial dye concentration $=$ $10 \mathrm{mg} \mathrm{L}^{-1}$, catalyst dosage $=1 \mathrm{~g} \mathrm{~L}^{-1}$ and $\mathrm{H}_{2} \mathrm{O}_{2}$ concentration $=15$ $\mathrm{mM})$. acidification with $\mathrm{H}^{+}{ }^{54}$ The positively charged surfaces of HPS$0.15 \mathrm{LFO}$ might inhibit the adsorption of dye due to the repulsive force, ${ }^{54}$ resulting in the observed slight decrease of degradation rate.

3.4.4 Effect of co-existing anions. As is well known, some of inorganic ions, including $\mathrm{NO}_{3}{ }^{-}, \mathrm{SO}_{4}{ }^{2-}$ and $\mathrm{Cl}^{-}$, are common coexisting ions with dyes in real wastewater originated from dyestuff industries, which might affect the degradation of RhB using HPS-0.15LFO.

In Fig. 11a, the coexistence of $\mathrm{NO}_{3}{ }^{-}$ion could slightly improve the degradation efficiency. Similar results were also reported by previous studies. ${ }^{55,56}$ The pseudo-first-order reaction rate constant $k$ was $0.0702 \mathrm{~min}^{-1}$ in the presence of $0.1 \mathrm{M}$ $\mathrm{NaNO}_{3}$. This may be explained by the photolysis of $\mathrm{NO}_{3}{ }^{-}$to produce hydroxyl radicals via the following reactions: ${ }^{57,58}$

$$
\begin{gathered}
\mathrm{NO}_{3}{ }^{-}+h \nu \rightarrow\left[\mathrm{NO}_{3}{ }^{-}\right]^{*} \\
{\left[\mathrm{NO}_{3}{ }^{-}\right]^{*} \rightarrow \mathrm{NO}_{2}{ }^{-}+\mathrm{O}^{-\cdot}} \\
\mathrm{O}^{-\cdot}+\mathrm{H}_{2} \mathrm{O} \rightarrow \cdot \mathrm{OH}+\mathrm{OH}^{-}
\end{gathered}
$$

The presence of $\mathrm{Cl}^{-}$and $\mathrm{SO}_{4}{ }^{2-}$ showed an inhibitory effect on the RhB photo-Fenton catalytic degradation using HPS-0.15LFO. The pseudo-first-order reaction rate constant $k$ was 0.0413 and $0.0280 \mathrm{~min}^{-1}$ when $\mathrm{NaCl}$ or $\mathrm{Na}_{2} \mathrm{SO}_{4}$ was added, in comparison of $0.0544 \mathrm{~min}^{-1}$ in the absence of coexisting ions. Eskandarloo et al. reported that $\mathrm{Cl}^{-}$could act as an effective scavenging agent of holes and/or hydroxyl radicals, ${ }^{59}$ thus lowering photo-Fenton-like catalytic degradation efficiency. This result is also in a good agreement with the literature. ${ }^{60}$ Similarly, the inhibitory effect of $\mathrm{SO}_{4}{ }^{2-}$ on the degradation was suggested by Konstantinou and coworkers that $\mathrm{SO}_{4}{ }^{2-}$ react with $\mathrm{h}^{+}$and ${ }^{\circ} \mathrm{OH}$ to form less reactive species $\mathrm{SO}_{4} \cdot{ }^{-}$(eqn (5) and (6)):: ${ }^{-1}$

$$
\begin{gathered}
\mathrm{SO}_{4}{ }^{2-}+\mathrm{h}^{+} \rightarrow \mathrm{SO}_{4} \cdot^{-} \\
\mathrm{SO}_{4}{ }^{2-}+\cdot \mathrm{OH} \rightarrow \mathrm{SO}_{4} \cdot^{-}+\mathrm{OH}^{-}
\end{gathered}
$$

On the other side, the competitive adsorption could more or less contribute to the observed reduction of degradation rates. $\mathrm{SO}_{4}{ }^{2-}$, as the double charged anion, might be easier to adsorb on the surface of HPS-0.15LFO as compared to $\mathrm{NO}_{3}{ }^{-}$and $\mathrm{Cl}^{-}$,
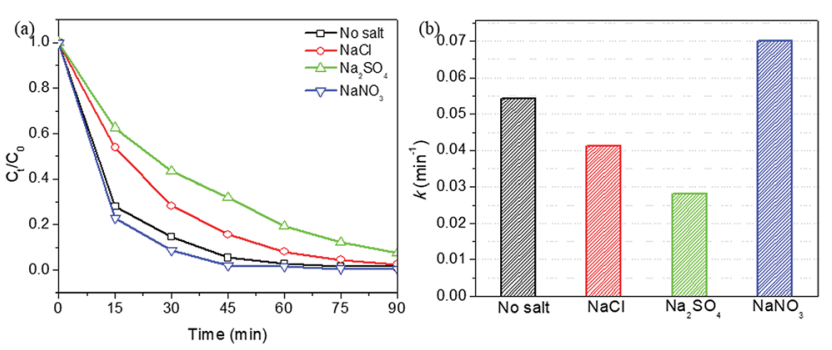

Fig. 11 (a) Effect of co-existing anions on removal of RhB in the photo-Fenton degradation and (b) degradation rate constants (reaction conditions: temperature $=25{ }^{\circ} \mathrm{C}$, initial dye concentration $=$ $10 \mathrm{mg} \mathrm{L}^{-1}$, catalyst dosage $=1 \mathrm{~g} \mathrm{~L}^{-1}, \mathrm{H}_{2} \mathrm{O}_{2}$ concentration $=15 \mathrm{mM}, \mathrm{pH}$ $=6, \mathrm{NaCl}, \mathrm{NaNO}_{3}$ or $\mathrm{Na}_{2} \mathrm{SO}_{4}=0.1 \mathrm{M}$ ). 
which potentially blocked more active site and in turn reduced degradation rate more significantly. ${ }^{56}$ The large molecular size of $\mathrm{SO}_{4}{ }^{2-}$ might also enhance steric hindrance and reduce the contact of RhB with HPS-0.15LFO. Consequently, the degradation efficiency appeared slightly lower in the presence of $\mathrm{SO}_{4}{ }^{2-}$ as compared with $\mathrm{Cl}^{-}$.

3.4.5 Stability and reusability. To study the stability and reusability of HPS-0.15LFO, it was collected after the photoFenton catalytic reaction and reused in a subsequent reaction cycle. As illustrated in Fig. 12a, no significant loss of photocatalytic activity was seen within four cycles of photo-Fenton catalytic degradation. The XRD patterns of HPS-0.15LFO before and after four cycles of RhB degradation (in Fig. 12b) show no noticeable difference. These suggest that HPS-0.15LFO can be effectively recycled and reused repetitively without significant reduction in catalytic activity. The ICP-MS analysis showed that the concentration of La and Fe in the solution after degradation was $4.67 \mathrm{mg} \mathrm{L}^{-1}$ and $0.064 \mathrm{mg} \mathrm{L}^{-1}$, respectively. The negligible concentration of dissolved ion detected implied that no significant contribution of homogeneous photo-Fenton reaction occurred. A slightly higher amount of dissolved La was detected; however, it did not play an essential role in contributing to catalytic degradation of RhB. The above results, including recycling use and XRD characterization, suggest the catalyst HPS-0.15LFO possessed good stability and reusability, thereby showing great potential for practical use in removing dyes and organics from wastewater.

3.4.6 Reaction mechanism. A possible mechanism for the photo-Fenton-like reaction using HPS-0.15LFO was proposed, as follows:

$$
\begin{gathered}
\equiv \mathrm{Fe}^{\mathrm{III}}+\mathrm{H}_{2} \mathrm{O}_{2} \rightarrow \equiv \mathrm{Fe}^{\mathrm{III}} \mathrm{H}_{2} \mathrm{O}_{2} \\
\equiv \mathrm{Fe}^{\mathrm{III}} \mathrm{H}_{2} \mathrm{O}_{2} \rightarrow \equiv \mathrm{Fe}^{\mathrm{II}}+\mathrm{HO}_{2}^{\cdot}+\mathrm{H}^{+} \\
\equiv \mathrm{Fe}^{\mathrm{III}}+\mathrm{HO}_{2}^{\cdot}+\mathrm{H}^{+} \rightarrow \equiv \mathrm{Fe}^{\mathrm{II}}+\mathrm{O}_{2}+2 \mathrm{H}^{+} \\
\equiv \mathrm{Fe}^{\mathrm{II}}+\mathrm{H}_{2} \mathrm{O}_{2} \rightarrow \equiv \mathrm{Fe}^{\mathrm{III}}+\cdot \mathrm{OH}+\mathrm{OH}^{-} \\
\mathrm{HPS}-0.15 \mathrm{LFO}+h \nu \rightarrow \mathrm{e}^{-}+\mathrm{h}^{+} \\
\mathrm{H}_{2} \mathrm{O}_{2}+\mathrm{e}^{-} \rightarrow \cdot \mathrm{OH}+\mathrm{OH}^{-}
\end{gathered}
$$
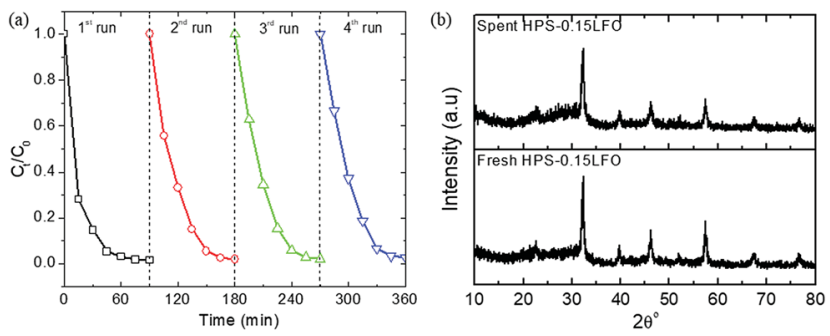

Fig. 12 (a) Recycling use of HPS-0.15LFO for RhB removal in the photo-Fenton reaction (reaction conditions: temperature $=25{ }^{\circ} \mathrm{C}$, initial dye concentration $=10 \mathrm{mg} \mathrm{L}^{-1}$, catalyst dosage $=1 \mathrm{~g} \mathrm{~L}^{-1}, \mathrm{H}_{2} \mathrm{O}_{2}$ concentration $=15 \mathrm{mM}, \mathrm{pH}=6$ ); (b) XRD patterns of the fresh HPS$0.15 \mathrm{LFO}$ before photo-Fenton-like catalytic degradation of RhB and the spent HPS-0.15LFO after four cycles of photo-Fenton-like catalytic degradation of RhB.

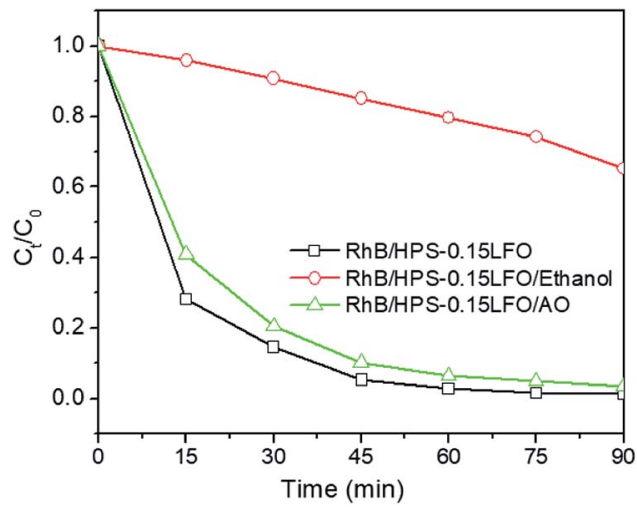

Fig. 13 Effect of ethanol and $\mathrm{AO}$ on the photo-Fenton-like catalytic degradation of RhB over HPS-0.15LFO (reaction conditions: temperature $=25^{\circ} \mathrm{C}$, initial dye concentration $=10 \mathrm{mg} \mathrm{L}^{-1}$, catalyst dosage $=$ $1 \mathrm{~g} \mathrm{~L}^{-1}, \mathrm{H}_{2} \mathrm{O}_{2}$ concentration $=15 \mathrm{mM}, \mathrm{pH}=6$ ).

$$
\begin{gathered}
\text { dye }+h \nu \rightarrow \text { dye }^{*} \\
\text { dye }^{*}+\mathrm{h}^{+} \rightarrow \text { dye }^{+} \\
\cdot \mathrm{OH}+\text { dye }\left(\text { or dye }{ }^{+}\right) \rightarrow \text { degradation products }
\end{gathered}
$$

It is commonly accepted that the interfacial Fe atoms (denoted as $\equiv \mathrm{Fe}^{\mathrm{III}}$ ) of perovskite-based catalysts can activate $\mathrm{H}_{2} \mathrm{O}_{2}$ to form hydroxyl radicals $\left({ }^{\circ} \mathrm{OH}\right)$ during the Fenton-like reaction (eqn (7)-(10)). ${ }^{8,62}$ The ${ }^{\circ} \mathrm{OH}$ radical is considered as a strong oxidizing agent because of its standard redox potential $(+2.8 \mathrm{~V})$, which could oxidize most of the dyes to the mineral end-products. ${ }^{63}$ Meanwhile, HPS-0.15LFO can absorb visible light to produce photogenerated electron-hole pairs (eqn (11)); ${ }^{64}$ the electron is trapped by $\mathrm{H}_{2} \mathrm{O}_{2}$ to generate highly reactive ${ }^{\circ} \mathrm{OH}$ (eqn (12)) and the hole is also an important active species to directly mineralize organic (eqn (14)). ${ }^{62}$ Note that the role of $\mathrm{h}^{+}$in oxidation process of organics has so far remained inconclusive. ${ }^{65}$ Some studies speculated that $\mathrm{h}^{+}$could activate dye*, which was formed after light absorption of dye (eqn (13)), into dye ${ }^{+}$(eqn (14)); dye ${ }^{+}$or dye was then oxidized by ${ }^{\circ} \mathrm{OH}$ radical (eqn (15)). ${ }^{66,67}$

To investigate the mechanism for photo-Fenton-like degradation over HPS-0.15LFO, the effect of active species, such as hole $\left(\mathrm{h}^{+}\right)$and hydroxyl radicals $\left({ }^{\circ} \mathrm{OH}\right)$, in the process was explored. Ethanol and ammonium oxalate (AO) were selected for use as the scavengers of ${ }^{\circ} \mathrm{OH}$ and $\mathrm{h}^{+}$in the trapping experiment, respectively. ${ }^{68,69}$ Fig. 13 shows that when $\mathrm{AO}$ was introduced, no significant change was observed in the photo-Fenton catalytic RhB degradation. However, when ethanol was added into the reaction solution, the $90 \mathrm{~min}$ RhB degradation efficiency was suppressed to only $47.3 \%$. It suggests that ${ }^{\circ} \mathrm{OH}$ play a more significant role in the photo-Fenton-like catalytic RhB degradation using HPS-0.15LFO.

\section{Conclusions}

The catalyst $\mathrm{LaFeO}_{3}$ supported by mesoporous silica (HPS) was successfully synthesized by the method of impregnation and 
subsequent calcination. The characterization results showed that the sample of HPS-0.15LFO with a theoretical LFO/silica molar ratio of 0.15 exhibited great surface area and a narrow bandgap. It exhibited higher total removal rate of RhB (98.9\%) from water compared to the others with different loadings of LFO; which was contributed to dark adsorption $(18.5 \%$ in 30 $\mathrm{min})$ and photo-Fenton degradation $(98.6 \%$ in $90 \mathrm{~min}$ in the presence of $15 \mathrm{mM} \mathrm{H}_{2} \mathrm{O}_{2}, 1 \mathrm{~g} \mathrm{~L}^{-1}$ catalyst and $\mathrm{pH}$ of 6). The optimum operational conditions for photo-Fenton degradation using HPS-0.15LFO were found to be: $\mathrm{RhB}$ concentration $=$ $10 \mathrm{mg} \mathrm{L}^{-1}$, catalyst dosage $=1 \mathrm{~g} \mathrm{~L}^{-1}, \mathrm{pH}=6$ and $\mathrm{H}_{2} \mathrm{O}_{2}=$ $15 \mathrm{mM}$. It is suggested that in this reaction, the hydroxyl radicals were the main active species. The high degradation efficiency, good reusability and stability may enable promising industrial application of HPS-0.15LFO as a visible-light-driven photo-Fenton-like catalyst for removal of organic from wastewater.

\section{Conflicts of interest}

There are no conflicts to declare.

\section{Acknowledgements}

T. Phan's PhD study is supported by Australia Awards Scholarship. This research was funded by Murdoch SEIT Small Grant Scheme (2016). The authors acknowledge the facilities, and the scientific and technical assistance of the Australian Microscopy \& Microanalysis Research Facility at the Centre for Microscopy, Characterisation \& Analysis, The University of Western Australia, a facility funded by the University, State and Commonwealth Governments.

\section{Notes and references}

1 E. Neyens and J. Baeyens, J. Hazard. Mater., 2003, 98, 33-50.

2 M. R. Carrasco-Díaz, E. Castillejos-López, A. Cerpa-Naranjo and M. L. Rojas-Cervantes, Chem. Eng. J., 2016, 304, 408-418.

3 K. Rusevova, F.-D. Kopinke and A. Georgi, J. Hazard. Mater., 2012, 241, 433-440.

4 M. Tekbaş, H. C. Yatmaz and N. Bektaş, Microporous Mesoporous Mater., 2008, 115, 594-602.

5 J. H. Ramirez, F. J. Maldonado-Hódar, A. F. Pérez-Cadenas, C. Moreno-Castilla, C. A. Costa and L. M. Madeira, Appl. Catal., B, 2007, 75, 312-323.

6 H. Zheng, Y. Pan and X. Xiang, J. Hazard. Mater., 2007, 141, 457-464.

7 J. M. Chacón, M. T. Leal, M. Sánchez and E. R. Bandala, Dyes Pigm., 2006, 69, 144-150.

8 L. Ju, Z. Chen, L. Fang, W. Dong, F. Zheng and M. Shen, J. Am. Ceram. Soc., 2011, 94, 3418-3424.

9 J. An, L. Zhu, Y. Zhang and H. Tang, J. Environ. Sci., 2013, 25, 1213-1225.

10 Y. Nie, L. Zhang, Y.-Y. Li and C. Hu, J. Hazard. Mater., 2015, 294, 195-200.

11 L. Li, X. Wang and Y. Zhang, Mater. Res. Bull., 2014, 50, 1822.
12 T. T. N. Phan, A. N. Nikoloski, P. A. Bahri and D. Li, J. Ind. Eng. Chem., 2018, 61, 53-64.

13 T. T. N. Phan, A. N. Nikoloski, P. A. Bahri and D. Li, J. Environ. Chem. Eng., 2018, 6, 1209-1218.

14 K. Rusevova, R. Köferstein, M. Rosell, H. H. Richnow, F.-D. Kopinke and A. Georgi, Chem. Eng. J., 2014, 239, 322331.

15 K. Peng, L. Fu, H. Yang and J. Ouyang, Sci. Rep., 2016, 6, 19723.

16 K. Wang, H. Niu, J. Chen, J. Song, C. Mao, S. Zhang and Y. Gao, Appl. Surf. Sci., 2017, 404, 138-145.

17 P. Xiao, J. Hong, T. Wang, X. Xu, Y. Yuan, J. Li and J. Zhu, Catal. Lett., 2013, 143, 887-894.

18 H. Su, L. Jing, K. Shi, C. Yao and H. Fu, J. Nanopart. Res., 2010, 12, 967-974.

19 X. Ren, H. Yang, S. Gen, J. Zhou, T. Yang, X. Zhang, Z. Cheng and S. Sun, Nanoscale, 2016, 8, 752-756.

20 S. Nguyen, V. Szabo, D. T. On and S. Kaliaguine, Microporous Mesoporous Mater., 2002, 54, 51-61.

21 J. Zhao, Y. Liu, X. Li, G. Lu, L. You, X. Liang, F. Liu, T. Zhang and Y. Du, Sens. Actuators, B, 2013, 181, 802-809.

22 W. Huang, X. Yu, J. Tang, Y. Zhu, Y. Zhang and D. Li, Microporous Mesoporous Mater., 2015, 217, 225-232.

23 K. Zhang, L.-L. Xu, J.-G. Jiang, N. Calin, K.-F. Lam, S.-J. Zhang, H.-H. Wu, G.-D. Wu, B. 1. Albela and L. Bonneviot, J. Am. Chem. Soc., 2013, 135, 2427-2430.

24 H. Li, J. Zhu, P. Xiao, Y. Zhan, K. Lv, L. Wu and M. Li, Microporous Mesoporous Mater., 2016, 221, 159-166.

25 S. Gai, P. Yang, L. Wang, C. Li, M. Zhang and L. Jun, Dalton Trans., 2012, 41, 4511-4516.

26 S. Merouani, O. Hamdaoui, F. Saoudi and M. Chiha, Chem. Eng. J., 2010, 158, 550-557.

27 S. K. Das, J. Bhowal, A. R. Das and A. K. Guha, Langmuir, 2006, 22, 7265-7272.

28 H. M. Gad and A. A. El-Sayed, J. Hazard. Mater., 2009, 168, 1070-1081.

29 S. Sachdeva and A. Kumar, J. Membr. Sci., 2009, 329, 2-10.

30 K. Shakir, A. F. Elkafrawy, H. F. Ghoneimy, S. G. Elrab Beheir and M. Refaat, Water Res., 2010, 44, 1449-1461.

31 M. Faryadi, M. Rahimi and M. Akbari, Korean J. Chem. Eng., 2016, 33, 922-933.

32 W. Wei, S. Guo, C. Chen, L. Sun, Y. Chen, W. Guo and S. Ruan, J. Alloys Compd., 2017, 695, 1122-1127.

33 J. Chandradass and K. H. Kim, Mater. Chem. Phys., 2010, 122, 329-332.

34 S. Perathoner, P. Lanzafame, R. Passalacqua, G. Centi, R. Schlögl and D. S. Su, Microporous Mesoporous Mater., 2006, 90, 347-361.

35 W. Dong, C. W. Lee, X. Lu, Y. Sun, W. Hua, G. Zhuang, S. Zhang, J. Chen, H. Hou and D. Zhao, Appl. Catal., B, 2010, 95, 197-207.

36 X. Li and J. Ye, J. Phys. Chem. C, 2007, 111, 13109-13116.

37 J. Zhao, T. Wu, K. Wu, K. Oikawa, H. Hidaka and N. Serpone, Environ. Sci. Technol., 1998, 32, 2394-2400.

38 M. Kruk, M. Jaroniec and A. Sayari, J. Phys. Chem. B, 1997, 101, 583-589. 
39 J. M. Rosenholm, T. Czuryszkiewicz, F. Kleitz, J. B. Rosenholm and M. Lindén, Langmuir, 2007, 23, 43154323.

40 P. Liao, Z. Malik Ismael, W. Zhang, S. Yuan, M. Tong, K. Wang and J. Bao, Chem. Eng. J., 2012, 195-196, 339-346.

41 P. Qin, Y. Yang, X. Zhang, J. Niu, H. Yang, S. Tian, J. Zhu and M. Lu, Nanomaterials, 2018, 8, 4.

42 S. Wang, H. Li, S. Xie, S. Liu and L. Xu, Chemosphere, 2006, 65, 82-87.

43 W. Wang, M. O. Tadé and Z. Shao, Chem. Soc. Rev., 2015, 44, 5371-5408.

44 J. Feng, X. Hu, P. L. Yue, H. Y. Zhu and G. Q. Lu, Ind. Eng. Chem. Res., 2003, 42, 2058-2066.

45 J. Feng, X. Hu, P. L. Yue, H. Y. Zhu and G. Q. Lu, Water Res., 2003, 37, 3776-3784.

46 R. Molina, F. Martínez, J. A. Melero, D. H. Bremner and A. G. Chakinala, Appl. Catal., B, 2006, 66, 198-207.

47 I. Arslan-Alaton, G. Tureli and T. Olmez-Hanci, J. Photochem. Photobiol., 2009, 202, 142-153.

48 Y. Gao, H. Gan, G. Zhang and Y. Guo, Chem. Eng. J., 2013, 217, 221-230.

49 P. P. Gan and S. F. Y. Li, Chem. Eng. J., 2013, 229, 351-363.

50 G. Wang, J. Qi, S. Wang, Z. Wei, S. Li, J. Cui and W. Wei, J. Dispersion Sci. Technol., 2017, 38, 632-641.

51 P. Singh, P. Raizada, S. Kumari, A. Kumar, D. Pathania and P. Thakur, Appl. Catal., A, 2014, 476, 9-18.

52 O. Bechambi, L. Jlaiel, W. Najjar and S. Sayadi, Mater. Chem. Phys., 2016, 173, 95-105.

53 J. R. Kim, S. G. Huling and E. Kan, Chem. Eng. J., 2015, 262, 1260-1267.

54 Y. Wang and W. Chu, Ind. Eng. Chem. Res., 2011, 50, 87348741.
55 X. Gao, X. Zhang, Y. Wang, S. Peng, B. Yue and C. Fan, Chem. Eng. J., 2015, 273, 156-165.

56 C. Wang, L. Zhu, M. Wei, P. Chen and G. Shan, Water Res., 2012, 46, 845-853.

57 L. Chu and C. Anastasio, J. Phys. Chem. A, 2003, 107, 95949602.

58 X. Zhang, Y. Wang and G. Li, J. Mol. Catal. A: Chem., 2005, 237, 199-205.

59 H. Eskandarloo, A. Badiei and M. A. Behnajady, Ind. Eng. Chem. Res., 2014, 53, 6881-6895.

60 H.-c. Liang, X.-z. Li, Y.-h. Yang and K.-h. Sze, Chemosphere, 2008, 73, 805-812.

61 I. K. Konstantinou and T. A. Albanis, Appl. Catal., B, 2004, 49, 1-14.

62 L. Li, X. Wang, Y. Lan, W. Gu and S. Zhang, Ind. Eng. Chem. Res., 2013, 52, 9130-9136.

63 I. K. Konstantinou and T. A. Albanis, Appl. Catal., B, 2004, 49, 1-14.

64 J. Yang, R. Hu, W. Meng and Y. Du, Chem. Commun., 2016, 52, 2620-2623.

65 W. Wang, M. O. Tadé and Z. Shao, Chem. Soc. Rev., 2015, 44, 5371-5408.

66 L. Li, X. Wang, Y. Lan, W. Gu and S. Zhang, Ind. Eng. Chem. Res., 2013, 52, 9130-9136.

67 Y. Soltanabadi, M. Jourshabani and Z. Shariatinia, Sep. Purif. Technol., 2018, 202, 227-241.

68 N. Daneshvar, D. Salari and A. Khataee, J. Photochem. Photobiol. A, 2003, 157, 111-116.

69 S. Meng, D. Li, M. Sun, W. Li, J. Wang, J. Chen, X. Fu and G. Xiao, Catal. Commun., 2011, 12, 972-975. 